\title{
Author Correction: Bottom-up synthesis of chiral covalent organic frameworks and their bound capillaries for chiral separation
}

\author{
Hai-Long Qian', Cheng-Xiong Yang ${ }^{1} \&$ Xiu-Ping Yan ${ }^{1,2}$
}

Correction to: Nature Communications; https://doi.org/10.1038/ncomms12104; published online 12 July 2016

This Article contains an error in Fig. 1, in which the structures of '(+)-Ac-L-Ta' and 'CTp' are drawn incorrectly. The correct version of Fig. 1 is shown below. The error has not been fixed in the original PDF and HTML versions of the Article.

Published online: 01 March 2019

\begin{abstract}
(c) (i) Open Access This article is licensed under a Creative Commons Attribution 4.0 International License, which permits use, sharing, adaptation, distribution and reproduction in any medium or format, as long as you give appropriate credit to the original author(s) and the source, provide a link to the Creative Commons license, and indicate if changes were made. The images or other third party material in this article are included in the article's Creative Commons license, unless indicated otherwise in a credit line to the material. If material is not included in the article's Creative Commons license and your intended use is not permitted by statutory regulation or exceeds the permitted use, you will need to obtain permission directly from the copyright holder. To view a copy of this license, visit http://creativecommons.org/licenses/by/4.0/.
\end{abstract}

(C) The Author(s) 2019

\footnotetext{
${ }^{1}$ College of Chemistry, Research Center for Analytical Sciences, State Key Laboratory of Medicinal Chemical Biology, Tianjin Key Laboratory of Molecular Recognition and Biosensing, Nankai University, 94Weijin Road, Tianjin 300071, China. ${ }^{2}$ Collaborative Innovation Center of Chemical Science and Engineering (Tianjin), 94 Weijin Road, Tianjin 300071, China. Correspondence and requests for materials should be addressed to X.-P.Y. (email: xpyan@nankai.edu.cn)
} 


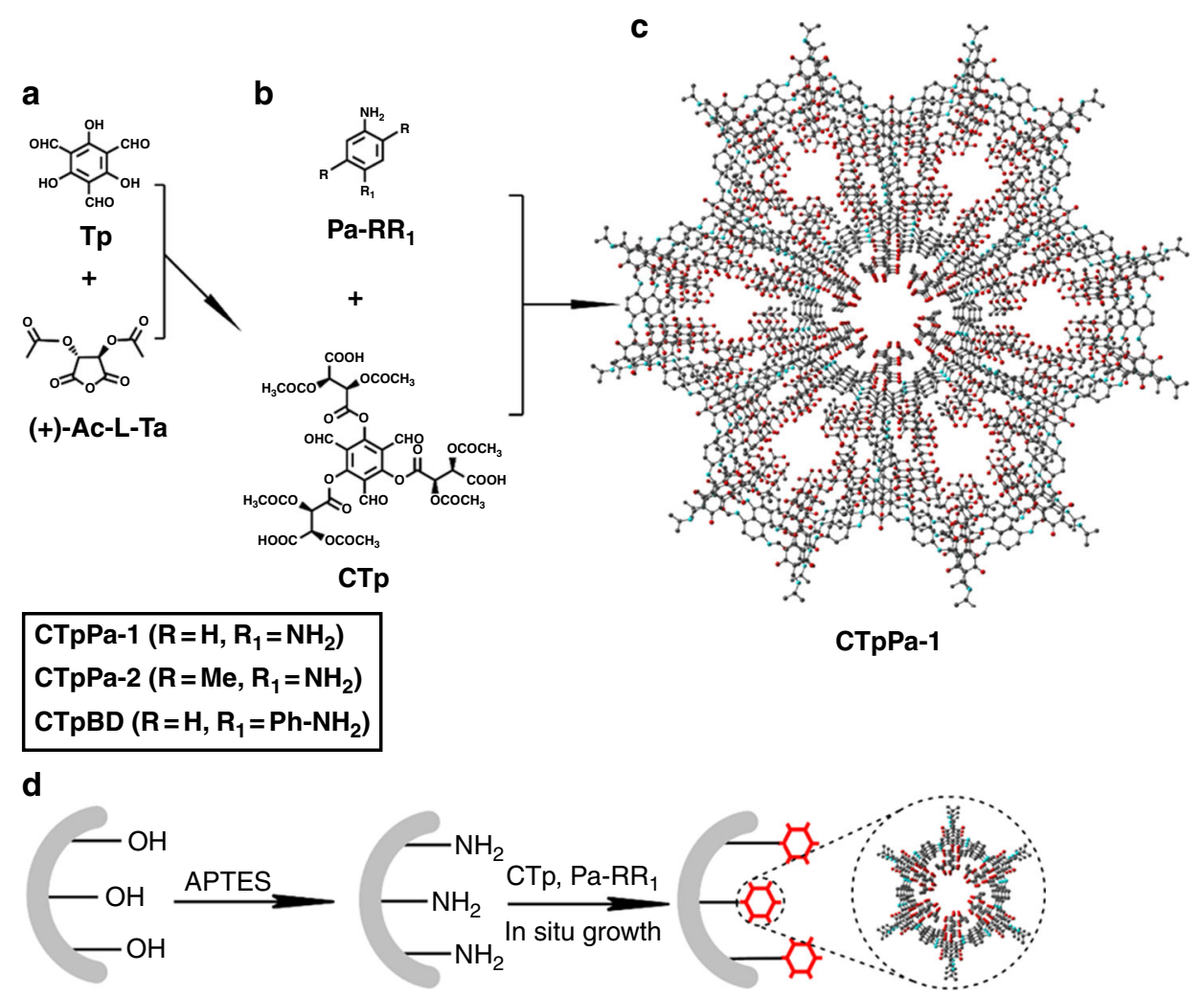

Fig. 1 